Berthier's test, agree better with each other than either agree with the calorimeter results.

On the average Berthier's test, when the empirical factor is used, appears to be more reliable than the results calculated from the analyses.

While the differences between the results obtained by different methods are not very great, they are certainly greater than can be accounted for by the errors of the work. In the case of two of the most important coals, the Lancaster and Brazil black, the relative value of the coals as given by the calorimeter, is reversed as given by the analyses and by Berthier's test. There can be little doubt that the calorimeter gives most accurately the relative heating value of these coals.

Attempts to make determinations with anthracite coals were unsuccessful, because it was found impossible to compress it into cylinders, and we have not yet been able to burn it in the form of a powder.

Some attempts have also been made to use the calorimeter of Barrus, ${ }^{1}$ but a deposit of carbon was always formed, and the results appeared to be entirely unreliable. It is probable that the results would be more satisfactory with anthracite coals.

TERRE HAUTE,

INDIANA.

\title{
TELLURIUM: ITS SEPARATION FROM COPPER RESIDUES WITH NOTES ON SOME NEW REACTIONS.?
}

\author{
BY CARELL Whitehead. \\ Received Sept. 9, 1895 .
}

\section{7} ELLURIUM which a few years ago was classed as a rare metal, is now known to be distributed over a very wide area, not only in our western states, but also in the gold producing states of the east. It occurs in the free state, and also combined with gold, silver, bismuth and many other metals. In the state of Colorado, tellurium is found in combination with gold and silver to such an extent, that the ores in many districts are rendered unfit for analgamation, and smelting and chlorination has to be resorted to. The separation of silver and gold from low grade

1 Trans. Mech. Eng., 14, 816. See als W. Thompson, loc. cit.

2 Read at the spring field meeting 
telluride ores, is a problem which, up to the present time, has baffled the skill of the metallurgists of the world. A few of the difficulties may be mentioned as follows: Tellurides do not give up their gold to mercury, cyanide or chlorine, they concentrate badly, a large percentage of the value being lost as slimes. They are difficult to roast, on account of their low melting-point and the loss of gold, during the removal of the tellurium. The usual course is to smelt this class of ore either with lead or copper ores. It is to the latter method I will call especial attention in this paper.

In order to work the copper ores of the west economically, they are smelted with gold and silver-bearing ores which act as flux, and also enrich the matte produced to a point where the cost of refining the copper is more than covered by the value of the precious metals contained. In this way large amounts of tellurium enter the matte. These mattes are Bessemerized in the west, and copper brought east to be refined by electrolysis. It contains from 98.5 to 99.5 per cent. copper, about roo ounces of silver, and three-tenths ounce of gold per ton. The impurities are arsenic, antimony, lead, bismuth, tellurium and selenium. The average amount of tellurium is not far fron 0.04 per cent. or 0.8 of a pound per ton. With the possible exception of the native copper of Lake Superior, it is doubtful if any copper produced is free from tellurium; this is certainly true of that from sulphide ores. I have already described a method for estimating the tellurium under these circumstances.'

The electric refining of such copper is carried on at Anaconda and at the Boston and Montana Copper Co: works at Great Falls, Montana; the Baltimore Electric Refining Co.,'Baltimore, Maryland; the Bridgeport Copper Co., Bridgeport, Conn., and the Ansonia Refinitig Co., Ansonia Connecticut; the Central Falls Electric Refining Co., Central Falls, Rhode Island; the Washburn and Moen Co., Worcester, Mass. and perhaps others.

In the Hayden process a bath of dilute copper sulphate, acidified with sulphuric acid is employed, in which is inserted an anode of rolled black copper and a cathode from a strip of pure copper, each being connected with the electric generator, while

1f. Am. Chem. Soc., 17, 280, $189,5$. 
disconnected plates of black copper are suspended in the bath between the two electrodes. When the current is on, solution takes place, not only at the anode but on all the disconnected plates interposed between the electrodes, and what is more interesting, this solution takes place on those surfaces of these plates which face the negative electrode, while the deposition of the pure copper takes place on the surface of the adjacent plate which faces the positive electrode. When the copper goes into the solution in its bath small amounts of some of the impurities in the copper enter into solution with it, but the greater portion remains either in the metallic state or are converted into oxides or basic salts which fall to the bottom of the bath where they form a black slimy residue.

The commercial refining of these residues is carried out as follows:

After screening out the coarser copper, the slimes are boiled with a twenty per cent. solution of sulphuric acid in a lead-lined tank by live steam, air being drawn in with the steam by means of a peculiar injector. During this boiling, practically all of the antimony, arsenic and bismuth salts, together with copper in the oxidized condition and that small portion of metallic copper which has been oxidized by the injected air go into solution.

After about one hour's boiling, a solution of silver sulphate is run in and steam applied for some minutes whereby according to the reaction $\mathrm{Cu}+\mathrm{Ag}_{2} \mathrm{SO}_{4}=\mathrm{CuSO}_{4}+\mathrm{Ag}_{2}$, the metallic copper still remaining is rapidly and completely converted into copper sulphate. Any excess of silver sulphate is removed by the addition of a fresh portion of slimes, when the solution is drawn off and the residue washed until free from copper salts. This residue, which has now lost the slimy, adhesive properties which characterized it and which consists of gold, silver, tellurium, and lead sulphate is pressed on a filter press. The pressed cakes are dried in an oven and then melted in a furnace, having a bed made of Portland cement, which is so arranged that a blast may be turned on. This quickly removes all but a trace of the lead present, together with portions of the tellurium and selenium.

The resulting bullion is poured into shoe-bars, weighing about 300 ounces each, it is about 950 fine, in silver and ten parts of 
gold. When cool these bars are dissolved in hot sulphuric acid, in a cast iron kettle, and when solution is complete the liquid is allowed to cool and settle for several hours, during which the gold falls to the bottom and the tellurium crystallizes out in white lustrous crystals of tellurous oxide. The first portion of the clear liquid is drawn off and precipitated by metallic copper, and the silver meited into bars 990 fine. The remainder is used in treating a fresh portion of the slimes.

The gold and the tellurous oxide are allowe to accumulate in the kettle until several hundred ounces are at hand, when they are removed and washed with dilute sulphuric acid and water, to remove silver, copper sulphate and tellurous oxide, and afterwards boiled in a small kettle with concentrated sulphuric acid to remove the remaining portion of silver and tellurium. When cool, and the gold has settled, the acid is again drawn off and the residue washed until free from tellurium and silver sulphates. The gold is now melted with borax and niter, by which any remaining traces of lead and tellurium are oxidized and slagged off, leaving fine gold, over 990 fine, the impurity being silver.

The washings from the gold residue contain the tellurium as tellurous oxide or tellurous sulphate. The tellurium may be obtained from these in two ways, after the removal of the silver as chloride. First, by precipitation with copper; second, by passing sulphur dioxide through the solution. It is better to use the first method, as large quantities of sulphur dioxide are very disagreeable to handle, and as the tellurium thus precipitated in the presence of copper is not pure and requires a further treatment. The metal used in this work was produced by inserting bars of copper into the solution and boiling with steam, a precipitate of cuprous telluride being obtained as a black powder. This was dried and then boiled with a five per cent. solution of sulphuric acid to remove the copper which had been oxidized during the drying process. After filtering, the mass is again moistened with five per cent. sulphuric acid and subjected to atmospheric oxidation with frequent stirring, then boiled again with more sulphuric acid and washed, this process is repeated until the copper is eventually very completely removed. Any copper left will combine with tellurium when fused and 
cause loss. The residue is now dried, mixed with three times its weight of sodium carbonate, and one-fourth its weight of charcoal, melted in a French clay crucible to quiet fusion, brought almost to a white heat, and the melt poured into a suitable mold. The cooled mass is crushed to a powder and the sodium telluride formed, dissolved out with boiled water; a great amount of heat is developed during the solution. The solution thus produced, which psssesses a rich port wine color, is filtered off, and the tellurium precipitated in the metallic state, by the passage of a current of air, as a fine gray powder, looking not unlike finely powdered galena. The tellurium is filtered and boiled with dilute hydrochloric acid, to remove traces of iron, aluminz, etc., washed and boiled for several hours, with a concentrated solution of potassium cyanide which removes selenium and most of the gold present. After drying, the tellurium is melted, without flux, in a French clay pot, the fine particles are made to run together by stirring, only a low temperature is necessary and the loss by volatilization is small. The metal still contains traces of impurities, the chief of which is gold. This would indicate that sodium telluride is a solvent of metallic gold, but this has not yet been proven. The tellurium is further purified by distillation in hydrogen gas.

NEW REACTIONS OF THE SALTS OF TELLURIUM.

If to a solution of the sodium or potasium tellurite is added a solution of an anmonium salt, such as the chloride or nitrate, a white precipitate is thrown down, which on boiling becomes granular.

$\mathrm{Na}_{2} \mathrm{TeO}_{3}+2 \mathrm{NH}_{4} \mathrm{Cl}=2 \mathrm{NaCl}+\mathrm{TeO}_{3}+2 \mathrm{NH}_{3}+\mathrm{H}_{2} \mathrm{O}$.

A small amount of tellurium dioxide or a metal which can be precipitated by sulphur dioxide remains in solution. It is the intention of the writer as soon as possible to examine and compare the properties of the metal from this fractional precipitation. While it is probable that tellurium oxide is slightly soluble in the alkali salts formed, which would explain incomplete precipitation, in view of the growing belief in the compound nature of tellurium, this reaction is deemed worthy of further investigation.

In an effort to purify tellurium, based upon the well-known property of hydrogen telluride of precipitating many of the 


\section{TELIURIUM: ITS SEPARATION FROM COPPER RESIDUES.}

metals from solution, the following reaction was observed, in addition to the one expected: $\mathrm{TeCl}_{4}+2 \mathrm{H}_{2} \mathrm{Te}=3 \mathrm{Te}+4 \mathrm{HCl}$. By passing this gas for some time into a solution of tellurium chloride, made slightly acid with hydrochloric acid, there was obtained a precipitate of tellurium and tellurides and a solution, from which sulphur dioxide threw down a precipitate of tellurium. After distillation in hydrogen I propose to determine the atomic weight of this purified metal.

When potassium ferrocyanide is added to tellurium chloride no change is observed at first but after a few hours Prussian blue is formed in large quantities.

\section{AIUMINUM TELLURIUE.}

Tellurium when heated with aluminum combines with explosive violence, forming a chocolate colored, difficultly fusible compound having the following composition by analysis.

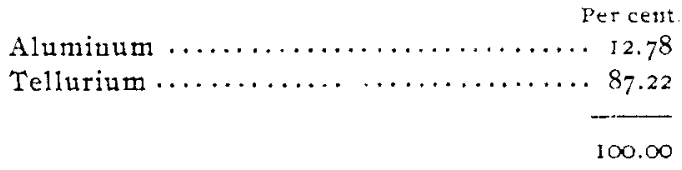

This corresponds closely to the formula $\mathrm{Al}_{2} \mathrm{Te}_{3}$ which requires

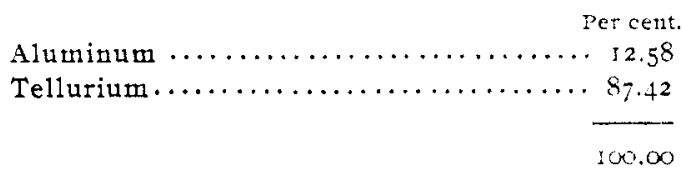

The violent chemical action attending its formation, joined with the fact that its composition remains constant, even in the presence of a large excess of aluminum, would indicate a true chemical combination and not an alloy, in the accepted sense. It is hard and brittle, can be easily ground to powder. When exposed to moist air it is slowly decomposed with the liberation of hydrogen telluride. When thrown into water hydrogen telluride is rapidly given off according to the following reaction: $\mathrm{Al}_{2} \mathrm{Te}_{3}+{ }_{3} \mathrm{H}_{2} \mathrm{O}=\mathrm{Al}_{3} \mathrm{O}_{3}+{ }_{3} \mathrm{H}_{4} \mathrm{Te}$ which corresponds to the well known sulphur reaction $\mathrm{Al}_{2} \mathrm{~S}_{3}+{ }_{3} \mathrm{H}_{2} \mathrm{O}=\mathrm{Al}_{2} \mathrm{O}_{3}+{ }_{3} \mathrm{H}_{2} \mathrm{~S}$. While comparing these two reactions it may be noted that hydrogen telluride is much more easily decomposed by oxygen than hydrogen sulphide. For example in treating aluminum telluride with 
water which has not been boiled fully one-half of the tellurium remains as metal: $\mathrm{H}_{2} \mathrm{Te}+\mathrm{O}=\mathrm{H}_{2} \mathrm{O}+\mathrm{Te}$. When treated with ninety-five per cent. alcohol no reaction takes place, even on boiling. This would seem to be the best one of the tellurides from which to make the organic salts as it does not decompose in the air so quickly as the alkali tellurides.

SEPARATION FROM COPPER BY THE ELECTRIC CURRENT.

Tellurium is easily deposited by the current, either from acid or alkaline solutions; even the feeblest current throws out the metal, but unfortunately not in the reguline state.

It has been found possible to separate tellurium fron copper by adding an excess of sodium hydroxide and about three grams of potassium cyanide for each gram of copper present. With this solution, a current such as is used for depositing copper, will throw out all the tellurium present, as a black non-adherent precipitate. After twelve hours, the tellurium is filtered off and weighed, either as metallic tellurium on a weighed filter or as tellurium dioxide. The solution is now made slightly acid with sulphuric and the copper precipitated in the usual way. If the proper amount of potassium cyanide has been added and the current has not been allowed to run too long, the tellurium is perfectly free from copper, and if the current is strong enough, none of it will adhere to the cathode.

Columbian University, Washington, $\boldsymbol{D}, \mathrm{C}$.

\section{THE ELECTROLYTIC REDUCTION OF PARANITRO COM- POUNDS IN SULPHURIC ACID SOLUTION.'}

By ARthur A. Noyes and John 'T. Dorrance.

Received September 9, 1895 .

INTRODUCTION.

I $T$ was shown some time ago by Noyes and Clement ${ }^{2}$ that nitrobenzene in sulphuric acid solution is transformed by electrolytic hydrogen into paraamidophenolsulphonic acid. It has since been proved by the extended investigations of Gattermann and his students ${ }^{3}$ that this behavior is characteristic of aromatic nitro compounds in general, one of the oxygen atoms

1 Read at the Spring field meeting.

2 Ber. d. chem. Ges., 26, 990.

8 Ibid, 26, 1844, $2810 ; 27,1927$. 